\title{
Violência sexual contra criança no meio intrafamiliar atendidos no SAMWIS, Teresina, PI
}

Sexual violence against children in a family environment attended by SAMVVIS, Teresina, PI

Violencia sexual contra niño en el medio intrafamiliar asistidos en el SAMVVIS, Teresina, PI

\section{Claudete Ferreira de Souza Monteiro', Delma Castelo Branco Soares Teles', Karoline Lopes Castro', Nayane Sieglyne Veras de Vasconcelos', Rosilane de Lima Brito Magalhães', Maria Castelo Branco Rocha de Deus'}

'Universidade Federal do Piauí. Núcleo de Estudos sobre Mulher e Relações de Gênero. Teresina, PI

\section{RESUMO}

O estudo se trata da caracterização da violência sexual em crianças atendidas no Serviço de Atendimento às Mulheres Vítimas de Violência Sexual (SAMVVIS) no período de 2004 a 2007, em Teresina, PI. Dados levantados em 229 registros indicam Que a idade das crianças vai de menores de I ano até os 12 anos. A identificação do agressor apresenta o vizinho (29,7\%), padrasto (1 I,4\%), pai (9,4\%) e tio com $8,4 \%$. Com relação à ocupação do agressor, 20,35\% são estudantes, desempregados (26,85\%) e aposentados (3,89\%). Conclui-se da necessidade de mais efetividade na política de proteção à criança, assim como de campanhas de alerta às mães Quando da escolha do guardador de suas filhas.

Descritores: Violência sexual; Criança; Enfermagem.

\begin{abstract}
This study deals with the characterization of sexual violence in children seen at the Services for the Assistance of Women Victims of Sexual Violence (SAMVIS) from 2004 to 2007 in Teresina, PI. Data collected from 229 charts indicate that the age of the children varies from less than one year up to 12 years of age. The identification of the aggressor was the neighbor (29.7\%), stepfather (11.4\%), father (9.4\%) and uncle with $8.4 \%$. In regards to the occupation of the aggressor, $20.35 \%$ are students, unemployed (26.85\%) and retired (3.89\%). It follows that there is the need for more efficiency in the policy of child protection and a need for campaigns to alert the mothers when choosing the caretakers of their daughters.
\end{abstract}

Descriptors: Sexual Violence; Children; Nursing.

\section{RESUMEN}

El estudio trata de la caracterización de la violencia sexual en niños asistidos en el Servicio de Asistencia a las Mujeres Víctimas de Violencia Sexual (SAMVVIS) en el periodo de 2004 a 2007, en Teresina, PI. Datos verificados en 229 registros cuyos resultados indican Que la edad de los niños va de menores de año hasta los 12 anos. La identificación del agresor presenta el vecino (29,7\%), padrastro (1 1,4\%), padre (9,4\%) y tío con $8,4 \%$. Con relación a la ocupación del agresor 20,35\% son estudiantes, desempleado (26,85\%) y jubilado (3,89\%). Se concluye la necesidad de más efectividad en la política de protección al niño y de campañas de alerta a las madres cuanto a la elección del guardián de sus hijas.

Descriptores: Violencia sexual; Niño; Enfermería. 


\section{INTRODUÇÃO}

A violência parece cada vez mais assolar a existência humana. A cada dia toma proporções maiores, afetando a sociedade como um todo, grupos ou famílias e, ainda, o indivíduo isoladamente.

Entre os fatores Que contribuem para desencadear a violência, encontram-se as desigualdades sociais, econômicas e culturais, desemprego, propagação das drogas, ou mesmo atos de perversidades cometidos pelo homem ${ }^{(1)}$.

A violência se apresenta sob várias formas, como física, psicológica, social e sexual. Entre estas, a violência sexual se destaca, já Que se configura como um tipo de agressão Que atinge a parte mais individual e reservada do ser humano - sua sexualidade. A violência sexual limita ou anula o exerć́cio dos direitos sexuais e reprodutivos da mulher.

No contexto da violência sexual, atualmente tem-se dado ênfase para o abuso contra criança e adolescentes, tornando-se um dos aspectos importantes no Plano Nacional de Políticas para as Mulheres, pelos agravos na saúde, pelo aumento das denúncias e por ser considerado pela sociedade como moralmente reprovável, além de um grave delito do ponto de vista jurídico.

Muitas vezes conhecida também como violência doméstica, o abuso infantil é todo ato ou jogo sexual no oual um indivíduo mais desenvolvido psicossexualmente tem com uma criança ou adolescente, no intuito de estimulá-la sexualmente ou garantir sua própria satisfação sexual ${ }^{(2)}$. Dessa forma, além da penetração dos órgãos sexuais, o simples to@ue nas genitais da criança ou uma situação contrária, já é considerado abuso sexual infantil.

Os abusos infantis são considerados relatos históricos. No Brasil, somente na década de 90 foi Que crianças e adolescentes passaram a ser juridicamente considerado como sujeitos de direitos, através da aprovação do Estatuto da Criança e do Adolescente (ECA). A partir de então, as crianças e adolescentes passaram a serem verdadeiramente tidos como cidadãos de direito à liberdade, à participação, à garantia à vida e ao bem-estar, e não mais como sujeitos indefesos, submissos, objetos de tutela e obediência ${ }^{(2)}$.

Pode-se apontar a violência contra criança no ambiente intrafamiliar como a Que mais ocorre mundialmente. $\mathrm{O}$ abuso parte principalmente de parentes próximos, como também vizinhos, amigos da família, ou seja, pessoas Que a criança tem um contato Quase que diariamente, o Que torna mais difícil a denúncia.

A ocorrência de maus tratos por parte da família da criança é hoje uma das preocupações de vários setores, e a ocorrência do abuso sexual por parte do pai, ou do padrasto da vítima, tem sido noticiada em vários estudos, revelando Que muitas vezes a mãe não denuncia pelo fato de não ter conhecimento do Que está acontecendo ou por medo de perder o companheiro ${ }^{(3)}$.

A família, Que deveria figurar como porto seguro de seus membros, torna-se, principalmente para as crianças abusadas física e sexualmente, como espaço de medo, conflitos e de incertezas entre o que é certo e o Que poderia estar acontecendo.

Nesse sentido, devido ao fato da criança não está preparada psicologicamente, ou ainda não ter noção ética e moral da atividade sexual, é quase que certo que ela desenvolva problemas emocionais depois de sofrer uma violência sexual, principalmente por não ter habilidade diante desse tipo de estimulação. Geralmente, a criança abusada sexualmente, principalmente por familiares ou pessoas significativas, desenvolve a perda da auto-estima, torna-se retraída, perde a confiança nos adultos e pode até chegar a considerar o suicídio, principalmente se a pessoa Que abusa ameaçar de violentála caso esta se negue a satisfazer seus desejos ${ }^{(4)}$.

No Piauí, o trabalho em torno da diminuição dos casos de abuso sexual infantil vem crescendo cada ano. Em 2004, foi criado o Serviço de Atendimento à Mulher Vítima de Violência Sexual (SAMVVIS), Que atende mulheres e crianças violentadas sexualmente e funciona em uma maternidade pública ${ }^{(5)}$. $\mathrm{O}$ atendimento se inicia neste serviço a partir de um registro de Boletim de ocorrência $\mathrm{BO}$, em delegacia da mulher.

A garantia de atendimento às mulheres Que sofreram violência sexual nos serviços de saúde representa, por conseguinte, apenas uma das medidas a serem adotadas com vista à redução dos agravos decorrentes deste tipo de violência. A oferta desses serviços, entretanto, permite a crianças, adolescentes e mulheres o acesso imediato de cuidados à saúde, a prevenção de doenças sexualmente transmissíveis e a gravidez indesejada.

Diante do fenômeno da violência sexual contra crianças, este estudo buscou caracterizar casos de violência sexual intrafamiliar em crianças atendidas no SAMVVIS, em Teresina/Piauí, no período de 2004 a 2007.

\section{METODOLOGIA}

O estudo constitui-se de uma pesquisa descritiva Quantitativa, realizada no SAMVVIS. A amostra foi constituída de 229 casos de abuso sexual, registrados no período de outubro de 2004 a novembro de 2007. A coleta de dados deu-se durante os meses de fevereiro e março de 2008, por informações retiradas diretamente dos registros dos prontuários dos atendimentos realizados.

Os critérios de inclusão no estudo foram casos de crianças vítimas de violência sexual no ambiente intrafamiliar e atendida no SAMVVIS, com faixa etária de 0 a 12 anos e residentes em Teresina - Piauí.

O estudo atendeu a todas as recomendações presentes na Resolução no 196/96 e só deu-se inicio à coleta após aprovação pelo Comitê de Ética e Pesquisa da NOVAFAPI e da Comissão de Ética do local onde foi realizado o estudo.

Os dados foram digitados e processados eletronicamente com a utilização do software SPSS, versão 12 , sendo apresentados em tabelas e gráficos, interpretados estatisticamente e analisados de acordo com o referencial teórico levantado sobre o tema.

\section{RESULTADOS}

Para se caracterizar os casos de violência sexual intrafamiliar em crianças atendidas no SAMVVIS, buscou-se inicialmente identificar o perfil das crianças abusadas, cujos dados revelam Que crianças menores de 1 ano até a idade de 12 anos todas são vitimizadas. Entretanto, os dados indicam Que as crianças nas idades de 11 e 12 anos foram as mais violentadas sexualmente no período da investigação.

Em relação à escolaridade dessas crianças, é possível verificar Que 42 crianças $(21,88 \%)$ ainda freQüentam o ensino primário e 107 (55,72\%) não concluíram o ensino fundamental, e Que 26 


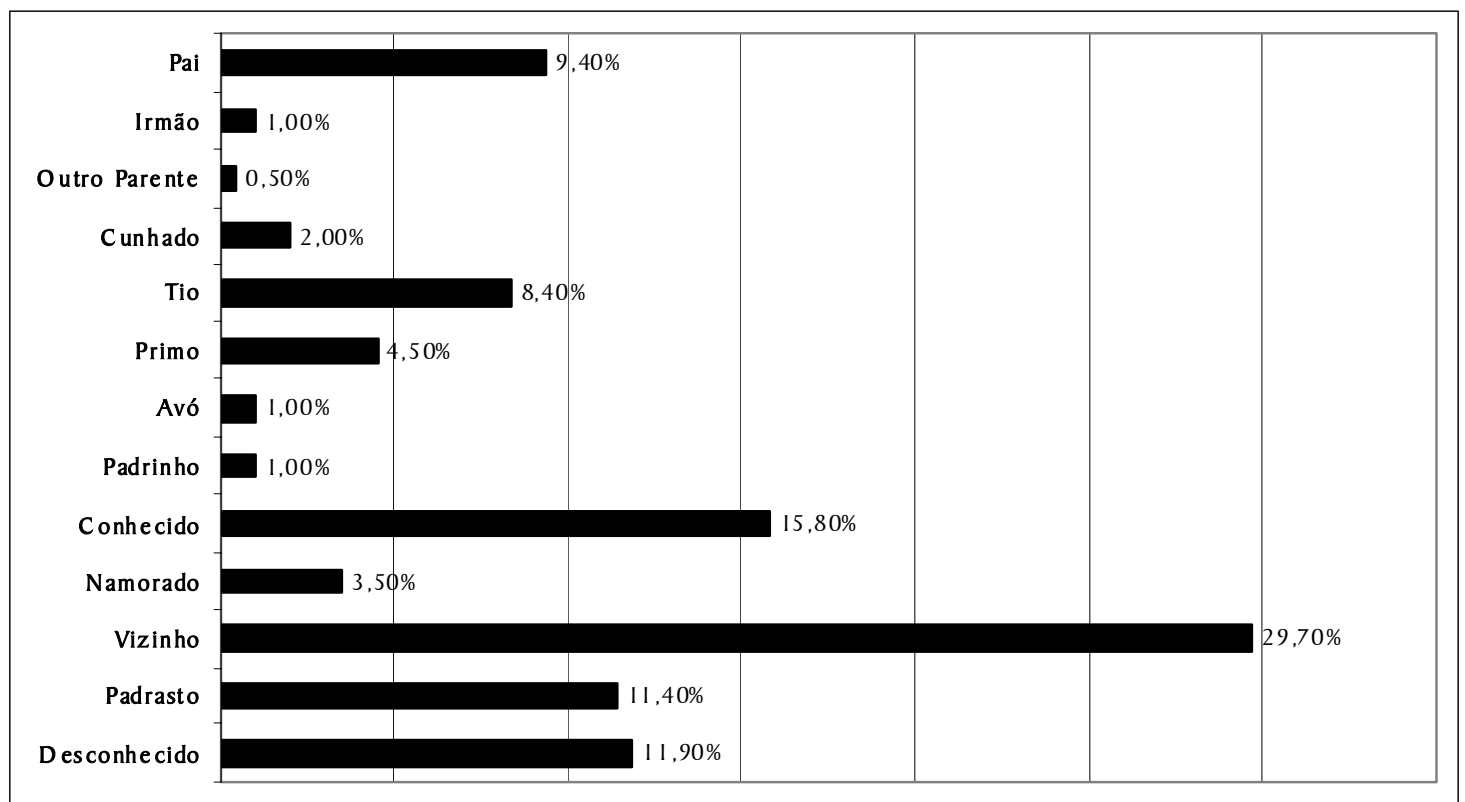

Gráfico I. Grau de parentesco do agressor. Teresina(PI), 2004-2007.

crianças $(13,54 \%)$ concluíram o ensino fundamental. Os dados mostram também Que 17 crianças $(8,85 \%)$ não estudam ou não estão ainda em idade de ingresso na área educacional.

Uma das variáveis do estudo referia-se ao perfil do agressor, e os dados levantados evidenciam que o agressor pode ser desde uma criança a um idoso. Nesse sentido, a faixa etária de 5 a 15 anos figura com 12 agressores, representando 7,19\%, e com mais de 60 anos a representatividade é de 5,39\%, equivalendo a 9 agressores. No entanto, há uma grande representatividade entre 15 e 25 anos, com $27,54 \%$, e na faixa etária compreendida entre 35 a 45 anos, com 26,95\%.

Quanto ao tipo de ocupação desse agressor, é possível verificar Que há maior prevalência entre estudantes (20,35\%), desempregados $(26,85 \%)$ e aposentados $(3,89 \%)$. Quanto à escolaridade do agressor, observa-se Que 24 (21,62\%) têm ensino fundamental completo, $26(8,92 \%)$ têm ensino fundamental incompleto e $12(6,22 \%)$ são analfabetos. Outro dado Que merece ser destacado é Que, entre os agressores, 4 têm ensino superior completo, representando 5,41\%, e 7 (9,46\%) possui ensino superior incompleto.

Com relação ao grau de parentesco do agressor com a criança abusada, o gráfico I mostra Que, em 15,8\% dos casos registrados no SAMVVIS, o agressor é uma pessoa conhecida da vitima, sendo representado em sua maior parte pelo vizinho $(29,7 \%)$, seguidos pelo padrasto (1 1,4\%), pai ( $9,4 \%$ ) e tio, com $8,4 \%$.

Quanto ao local de agressão e verifica-se Que a maioria dos casos acontece no ambiente familiar (47\%) e na residência do agressor, com $22,3 \%$. Os demais casos acontecem em via pública $(16,7 \%)$, nas escolas $(2,3 \%)$ e outros locais $(11,6 \%)$.

Com relação ao turno em Que acontecem as agressões sexuais, verificou-se Que $32,96 \%$ ocorreram no período matutino, 36,31\% no período vespertino e $30,73 \%$ noturno. O Que mostra Que a agressão acontece em todos os turnos, sendo registrado com maior freqüência no período vespertino.

Quanto ao uso de arma pelo agressor, e os dados revelam Que em $94,8 \%$ das denúncias o agressor não fez uso de arma para violentar sexualmente as crianças, ao passo Que 5,2\% fizeram uso de armas.

\section{DISCUSSÃO}

Analisando os dados coletados sobre o perfil das crianças, verificou-se considerável número de crianças, todas do sexo feminino, Que foram sexualmente violentadas e com registro no SAMVIS no período compreendido entre 2003 a 2007 . Apesar desse elevado número, os dados não são a sua totalidade, pois há consenso nos estudos de Que o número de casos não relatados seja maior do Que os notificados. Em relação ao sexo feminino, leva-se em conta Que este serviço só atende mulheres, mesmo Que o abuso sexual seja mais frequentemente identificado nas meninas, e importa a análise de Que os meninos são tão vítimas Quanto às meninas. $\mathrm{O}$ Que os diferencia é o fato de Que as crianças do sexo masculino têm mais dificuldades para revelar Que foram abusadas, e, ainda, considerando Que os profissionais de saúde, por sua vez, também têm mais dificuldade para identificarem esse tipo de abuso nos meninos ${ }^{(6)}$.

Em relação à idade, a violência sexual é praticada em crianças com idade inferior a um ano, mas figura em todas as idades até atingir os 12 anos, com maior prevalência à medida Que se aproxima da adolescência. Este dado acompanha outros, pois a média de idade das crianças do sexo feminino Que são abusadas sexualmente é de 9,2 $\operatorname{anos}^{(7)}$. Assim, é provável Que estes adolescentes não tenha ainda iniciado a atividade sexual. Portanto, além do risco da gravidez indesejada, pela falta do uso do anticoncepcional, as lacerações traumáticas também são maiores, aumentando o risco para HIV e DST ${ }^{(8)}$.

Essas alterações na saúde da criança nem sempre é a primeira 
preocupação, pois rotineiramente a família se interessa mais em denunciar o agressor, o Que prejudica o acompanhamento de crianças e adolescentes pelo seguimento ambulatorial. Este é pouco freQüente, talvez pela falta de percepção do responsável Quanto à importância desse acompanhamento ou mesmo porQue não esteja motivado e consciente da importância desse acompanhamento, tanto nos seus aspectos físico como psicológicos.

Outro fator Que limita tanto a denúncia Quanto o seguimento ambulatorial é que a família prefere encaminhar a criança para outro bairro ou mesmo outro município, na concepção de Que com esta atitude irá preservar a imagem da criança, minimizando o estigma na comunidade em Que reside.

Vale destacar Que o Ministério da Saúde recomenda, em sua Norma Técnica 06/2005, Que a mulher vitima de violência sexual precisa ser acompanhada por uma rede integrada de serviço ${ }^{(9)}$. Esta falta de acompanhamento é motivo de preocupação do setor saúde, pois estudos revelam Que a pessoa vitima de violência sexual pode ter uma baixa auto-estima, além de pânico e medo ${ }^{(5)}$.

Neste sentido, a família desenvolve um importante papel na proteção da criança desde a sua concepção. No entanto, com a evolução da sociedade, tem-se mudado também os valores culturais referentes ao cuidado da criança, pois, com a inserção da mulher no processo de trabalho, este cuidado passou a ser desenvolvido por uma segunda pessoa. O Ministério da Saúde destaca a importância da proteção individual, de acordo a idade e gênero, proteção familiar visualizada na saúde mental dos pais e proteção social Que se caracteriza pelo bom relacionamento na escola, instituição de trabalho e família(10).

Com relação à escolaridade, essas crianças encontram-se ainda inseridas no ensino fundamental ( $\mathrm{I}^{\mathrm{a}}$ a $4^{\mathrm{a}}$ série), sendo Que apenas um pequeno número aparece como não estudando, o Que pode ser associado ao número de crianças em idade menor de dois anos. A educação se torna uma importante ferramenta de proteção às mulheres, uma vez que além de lhes ensinar a ler e escrever permite a elas conhecer seus direitos e traz uma nova consciência do papel delas no mundo de hoje $\mathrm{e}^{(11)}$. Entretanto Quando a criança e adolescentes são sexualmente abusadas podem ocorrer alguns aspectos sociais como o abandono da escola e a prostituição $0^{(12)}$.

Entretanto, na maioria das famílias de classe media baixa a participação dos pais, no Que se refere ao acompanhamento escolar, é pouco freqüente, deixando sobre a responsabilidade da escola a educação dos seus filhos. O processo de formação da criança envolve a família e a escola, sendo Que esta última tem papel complementar ao da família ${ }^{(13)}$. A escola constitui também lugar privilegiado para detecção de casos de violência sexual, uma vez Que o agressor, no geral, é pessoa conhecida da criança. No entanto, a maioria dos educadores possui pouca abordagem sobre a temática e, além disso, os mesmos realizam condutas inadequadas diante de situações de violência.

Com relação à idade do agressor, o estudo mostra Que este se encontra em uma condição favorável em força física, desenvolvimento da maturação sexual e maior capacidade de acesso à criança. Outros levantamentos já realizados revelam Que o agressor, além da relação de poder para com a criança, utiliza-se também da confiabilidade Que a mesma tem nele, Quando em suas atitudes demonstra carinho e afetividade, sendo compreendido pela criança como uma atitude normal, passando-lhe a idéia de $\operatorname{proteção~}^{(14)}$.

No tocante à ocupação, observa-se Que o agressor foi maior representado por desempregados, estudantes e aposentados, indicando Que o mesmo dispõe de tempo para prestar assistência à criança e adeuirir sua confiabilidade por meio de brincadeiras aparentemente saudáveis. Este pensamento vai de encontro a outros estudos que também acrescentam que os abusos se tornam cada vez mais freQüentes, levando ao sentimento de insegurança e dúvida em relação à sua proteção, visto Que o agressor é uma pessoa responsável para a família; e mesmo assim a criança fornece sinais indiretos $^{(14)}$.

Os agressores são representados por todos os níveis de escolaridade. No entanto, há uma maior prevalência em escolaridade mais baixa. No Brasil, as condições ambientais adversas são facilitadoras de abuso sexual em crianças, e o maior número de casos é registrado em crianças de condição social inferior. Ressaltamse também as muitas dificuldades enfrentadas por grande parte das meninas brasileiras em conseqüência das agruras da pobreza, oriundas de lares com baixo rendimento familiar, o Que as colocam em situação de vulnerabilidade à violência Quando são deixadas por suas mães em casas de vizinhos e parentes mais desocupados eneuanto seus pais buscam o sustento do lar.

Outro fator poderia estar associado a pessoas com baixa autoestima, controle deficiente de seus impulsos, dificuldade para lidar com o stress, o Que lhes tornariam mais vulneráveis a praticar atos de violência ${ }^{(10)}$.

Referente ao perfil do agressor, este estudo identificou, nos registros do SAMVVIS, o vizinho como o principal agressor, diferente de outras pesquisas que apontam o pai e o padrasto como o principal agressor ${ }^{(3)}$. Entretanto, o Ministério da Saúde coloca Que a violência sexual Que acomete crianças e adolescentes vem sendo praticada por pais, educadores e responsáveis e em abrigos e internatos ${ }^{(15)}$. Quando, porém, o abuso é realizado pelo pai, além da violência sexual, a criança fica também mais vulnerável à violência psicológica, a partir do momento Que a criança começa a entender o abuso, e então o agressor usa a insegurança da criança para desenvolver sentimentos de culpa por esta ter aceitado o seu carinho $^{(14)}$.

No tocante ao local de agressão, o registro é expressivo para o ambiente familiar do agressor ou da vitima. O convívio familiar deve ser percebido pela criança como local de grandes alegrias, segurança, caracterizado por seus valores como, por exemplo, os brineuedos. No entanto, isso não é a realidade de todas as crianças, pois algumas são ameaçadas de violência desde o nascimento, refletindo no seu desenvolvimento psíquico e motor.

No tocante ao uso de armas, a maioria dos agressores não utiliza instrumento para persuadir a criança durante o abuso sexual, diferentemente do Que acontece no abuso sexual à mulher, pois neste é comum o uso de armas de fogo ${ }^{(16)}$. Pode-se analisar Que a violência sexual à criança normalmente é realizada por um agressor conhecido e se processa de maneira gradativa, como caricias e beijos, aos poucos permitindo ao agressor a oportunidade de intimidar a criança com seus agrados até a realização da violência sexual ${ }^{(14)}$.

Referente ao turno da agressão, observa-se Que este se realiza em todos os turnos, portanto não há um horário preferencial, basta Que o agressor se encontre a sós com a criança para Que o abuso aconteça. 


\section{CONCLUSÕES}

O estudo permite afirmar que a saúde da criança depende de um contexto abrangente, no Qual se destaca a proteção da criança em relação a situações de risco, principalmente relacionado à violência sexual, pois esta favorece ao aparecimento de outros agravos, prejudicial ao seu desenvolvimento saudável.

Conclui-se, também, Que os casos de abuso sexual praticados em crianças em Teresina encontram-se cada vez mais numerosos e a sua visibilidade hoje já é possível graças ao SAMVVIS.

O estudo traz um dado diferencial, chamando atenção para o agressor, como sendo, em sua maioria, os vizinhos, o Que gera a necessidade de iniciativas mais efetivas na política de proteção à criança e de ação conjunta dos vários setores para avançar na repressão de tais atos e promover eventos e campanhas para conscientização e prevenção da violência sexual praticada em crianças, alertando principalmente as mães Quando da escolha do guardador de suas filhas e filhos.

Neste sentido, o profissional Enfermeiro tem a possibilidade de contribuir com essas ações por meio de atividades desenvolvidas com as mães, como por exemplo, na consulta de enfermagem e na educação em saúde, pois a violência à criança normalmente se processa por um longo período de tempo, imperceptível às vezes ao olhar da própria mãe.

\section{REFERÊNCIAS}

1. Araújo MF. Violência e abuso sexual na família. Psicol Estudo 2002; 7(2) 3-11.

2. Ribeiro MA, Ferriani MGC, Reis IN. Violência sexual contra crianças e adolescentes: características relativas à vitimização nas relações familiares. Cad Saúde Pública 2004; 20(2): 456-64.

3. Habigzang LF, Koller SH, Azevedo, GA, Machado, PX. Abuso sexual infantil e dinâmica familiar: aspectos observados em processos jurídicos. Psicol Teoria Pese 2005; 2 I (3): 43 I-48.

4. Ballone CI. Abuso Sexual Infantil. Disponível em: URL: http:/ /www.virtualpsy.org/infantil/abuso.html.

5. Viana F. SAMVVIS atende 20 mulheres vítimas por mês. Governo do Estado do Piauí. Teresina(PI): 2007 [citado I jun 2007]. Disponível em: URL: http://www.pi.gov.br/materia

6. Ministério da saúde (BR). Curso de Impacto da violência na saúde. Módulo II.Atenção a pessoas em situação de violência sob as perspectivas do ciclo de vida e das vulnerabilidades. Brasília (DF): Ministério da Saúde; 2007.

7. Seabra AS. Abuso sexual na infância. Cad Psiquiatria 2008.

8. Diniz NMF, Almeida LCG, RIBEIRO, BCS, Macedo VG. Mulheres Vitimas de violência sexual: adesão a Quimioprofilaxia do HIV. Rev Latino-am Enfermagem 2007; 15(I): 7-12.

9. Ministério da Saúde (BR). Secretaria de Atenção à Saúde. Departamento de Ações Programáticas Estratégicas. Área
Técnica de Saúde da Mulher. Prevenção e Tratamento dos Agravos resultantes da Violência Sexual contra Mulheres e Adolescente norma técnica. $2^{\mathrm{a}}$ ed. Brasília (DF): Ministério da Saúde; 2005.

10. Ministério da Saúde (BR). Curso de Impacto da violência na saúde. Módulo I. Bases conceituais e históricas da violência e setor saúde. Brasília (DF): Ministério da Saúde; 2007.

11. Mai M. Desonrada - depoimento. Rio de Janeiro (RJ): Best Seller; 2007.

12. Monteiro CFS, Costa NSS, Nascimento PSV, Aguiar YA. Violência intrafamiliar contra adolescentes grávidas. Rev Bras Enferm 2007; 60 (4): 373-6.

13. Tiba I. Quem ama educa. São Paulo (SP): Gente; 2002.

14. Pfeiffer L, Salvagni EP. Visão atual do abuso sexual na infância e adolescência. J Pediatr 2003; 8 I(5).

15. Ministério da Saúde (BR). Secretaria de Assistência a Saúde. Notificação de Maus-Tratos contra criança e adolescentes pelos profissionais de saúde: um passo a mais na cidadania em saúde/ Ministério da Saúde, Secretaria de Assistência a Saúde. Brasília (DF): Ministério da Saúde; 2002.

15. Lopes IMRS, Gomes KRO, Silva BB. Caracterização da violência sexual em mulheres atendidas no projeto Maria- Maria em Teresina- PI. Rev Bras Ginecol Obstet 2004; 26(2): 1 I 1-6. 